\title{
Effects of dust storms on microwave radiation based on satellite observation and model simulation over the Taklamakan desert
}

\author{
J. Ge ${ }^{1}$, J. Huang ${ }^{1}$, F. Weng ${ }^{2}$, and W. Sun ${ }^{3}$ \\ ${ }^{1}$ College of Atmospheric Sciences, Lanzhou University, Lanzhou, China \\ ${ }^{2}$ NOAA/NESDIS, Camp Springs, Maryland, USA \\ ${ }^{3}$ Dept. of Atmospheric Sciences, Hampton University, Hampton, Virginia, USA
}

Received: 17 March 2008 - Published in Atmos. Chem. Phys. Discuss.: 22 April 2008

Revised: 3 July 2008 - Accepted: 17 July 2008 - Published: 27 August 2008

\begin{abstract}
Effects of dust particles on microwave radiation over the Taklamakan desert are studied with use of measurements from the Advanced Microwave Scanning Radiometer (AMSR-E) on the EOS Aqua satellite and a microwave radiation transfer model. Eight observed cases show that the signal from atmospheric dust can be separated from the surface radiation by the fact that the dust particles produce stronger scattering at high frequencies and depolarize the background desert signature. This result of satellite data is consistent with the model simulation.
\end{abstract}

\section{Introduction}

Taklamakan is the second largest desert in the world and a major source of dust aerosols in East Asia. The strong winds often stir up surface sand, lift small particles and trigger monster dust storms. The most serious dust storms, called blind dust storms, can cause near-zero visibility. There are nearly 60 sandy days throughout a year over Taklamakan desert, and most of dust particles are transported into the atmosphere and form a layer of dust aerosols. These dust particles have been recognized as important atmospheric constituents because dust particles influence the global climate by scattering and absorbing solar radiation, and absorbing and emitting outgoing longwave radiation (Twomey et al., 1984; Albrecht, 1989; Resenfeld et al., 2001; DeMott et al., 2003; Huang et al., 2006; Slingo et al., 2006). Recently, Huang et al. (2007) use the Cloud-Aerosol Lidar and Infrared Pathfinder Satellite Observations (CALIPSO) to monitor the dust aerosols originated from the Taklamakan desert and point out that these dust plumes even can sack up against the northern slope of

Correspondence to: J. Huang

(hjp@lzu.edu.cn)
Tibetan Plateau, these dust plumes over Tibetan Plateau may alter the atmospheric circulation and lead to an earlier onset and intensification of the Indian monsoon (Lau and Kim, 2006). The aerosols associated with dust storms can also pose a serious health risk for people with respiratory disorders. It is imperative to monitor the dust storms and predict their evolution for both climate and environment researches.

Several techniques have been developed for detecting and tracking dust storms. One of the detection methods is based on brightness temperature differences (BTD) either in two or three thermal-infrared channels (Prata, 1989; Ackerman, 1997; Legrand et al., 2001; Prata and Grant, 2001). This approach enables people to discriminate dust from the clear sky over oceans and land. Limited work has been done on the sensitivity of microwave radiation to aerosols including volcanic ash (Delene et al., 1996) and in particular dust storms (El-Askary, 2003 and 2006). The lack of interests in using microwave measurements for dust storm detection may be due to incomplete knowledge on dust particle size relative to the wavelength (or size parameter). In general, microwave radiation can penetrate through the dust storm with little attenuation when the size parameter is small. From recent insitu measurements, the dust aerosols can be as large as a millimeter size. Such particles can also be charged as well (Yang et al., 2003).

El-Askary (2003) studied dust storms using Tropical Rainfall Measuring Mission (TRMM) Microwave Imager (TMI) data. At microwave frequencies, dust particles could scatter significant amount of radiation as identified by the scattering index (SI) which was developed by Ferraro and Grody (1994) for precipitation monitoring. In this study, we further examine the effects of dust storms on the AMSR-E brightness temperatures $(\mathrm{Tb})$ and use the brightness temperatures to deduce the information on dust particles.

Published by Copernicus Publications on behalf of the European Geosciences Union. 

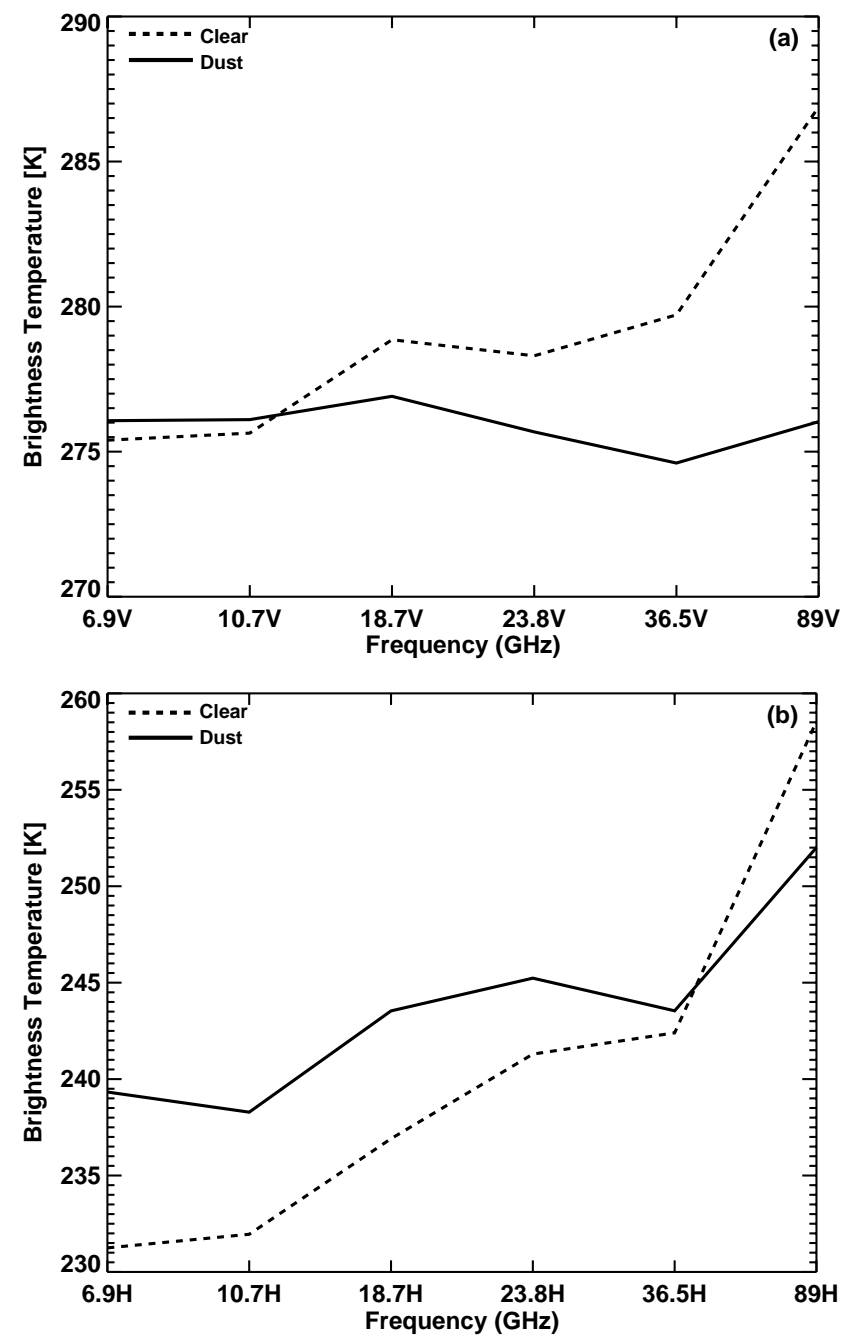

Fig. 1. Comparison of polarized brightness temperature of the dust case on 18 March 2005 and clear sky values of March 2005 as function of frequency. Upper panel is for vertical $\mathrm{Tb}$, lower is for horizontal.

\section{Data and model}

The data used in this study are from the Advanced Microwave Scanning Radiometer (AMSR-E) onboard the NASA EOS Aqua satellite which was launched in May 2003. The AMSR-E has 12 channel polarization measurements at six frequencies in a range of 6.9 to $89 \mathrm{GHz}$. It conically scans the whole globe in two days as it ascends and descends around the earth. The AMSR-E antenna temperature was converted to brightness temperatures using the method proposed by Wentz (1998). For the period of 2003 to 2006, we have identified and collected eight dust storm cases (see Table 1) over the Taklamakan desert.

The model used in this study is a vector discrete ordinate microwave radiative transfer (V-DISORT) program (Weng, 1992), which is applied to simulate microwave radiation

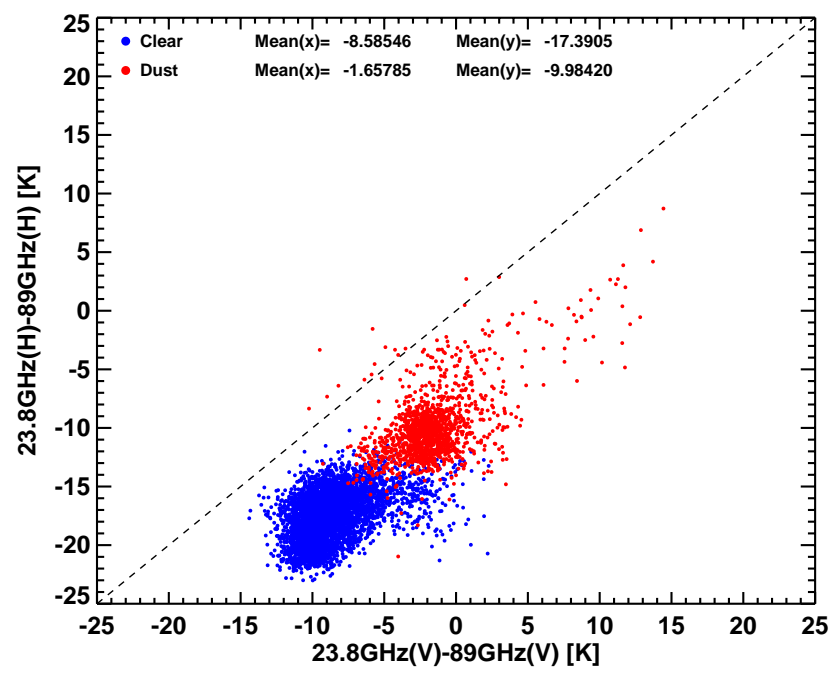

Fig. 2. Comparison of the brightness temperature difference (in $\mathrm{K}$ ) between $\mathrm{T}_{23.8 \mathrm{GHz}(\mathrm{V})}-\mathrm{T}_{89 \mathrm{GHz}(\mathrm{V})}$ and $\mathrm{T}_{23.8 \mathrm{GHz}(\mathrm{H})}-\mathrm{T}_{89 \mathrm{GHz}(\mathrm{H})}$ for eight dust cases. The blue color represents the clear data and red the dust.

Table 1. Eight dust cases used in this study.

\begin{tabular}{rllll}
\hline Case & Date & GMT & Lat $\left({ }^{\circ} \mathrm{N}\right)$ & Lon $\left({ }^{\circ} \mathrm{E}\right)$ \\
\hline 1 & $04 / 09 / 2003$ & $07: 14$ & $38.7-39.3$ & $78.0-78.8$ \\
2 & $03 / 12 / 2004$ & $07: 02$ & $38.9-39.3$ & $81.0-82.0$ \\
3 & $04 / 23 / 2004$ & $07: 39$ & $37.5-38.0$ & $78.8-80.2$ \\
4 & $01 / 30 / 2005$ & $06: 38$ & $38.4-39.5$ & $81.5-83.5$ \\
5 & $03 / 18 / 2005$ & $06: 38$ & $36.3-36.7$ & $80.7-82.0$ \\
6 & $03 / 13 / 2006$ & $06: 44$ & $38.8-39.7$ & $78.3-81.2$ \\
7 & $03 / 14 / 2006$ & $07: 27$ & $38.0-39.0$ & $78.0-80.0$ \\
8 & $03 / 15 / 2006$ & $06: 31$ & $36.8-37.7$ & $80.5-83.0$ \\
\hline
\end{tabular}

transfer in the atmosphere. The effects of dust particles on microwave radiation are simulated by this model with an assumption of spherical dust particle shapes.

\section{Analysis and results}

The particle sizes of sand and dust over the Taklamakan desert are mainly in a range of $0.002-0.2 \mathrm{~mm}$ (Yang et al., 2003). Strong winds not only lift small dust aerosols into the air higher than $1 \mathrm{~km}$ but also form a horizontal flow of large particles within a boundary layer about $1.5 \mathrm{~m}$ in thickness. Both dust particles suspending in the air and flowing near the surface can have a significant impact on microwave radiation transfer.

In this study, we examine the effect of dust storms on the AMSR-E Tb and use it to deduce the signal of dust particles. Figure 1 compares the mean $\mathrm{Tb}$ for both vertical and horizontal polarizations from the dust storm case on 18 March 2005 with those from the clear sky cases on March 2005. At verti- 


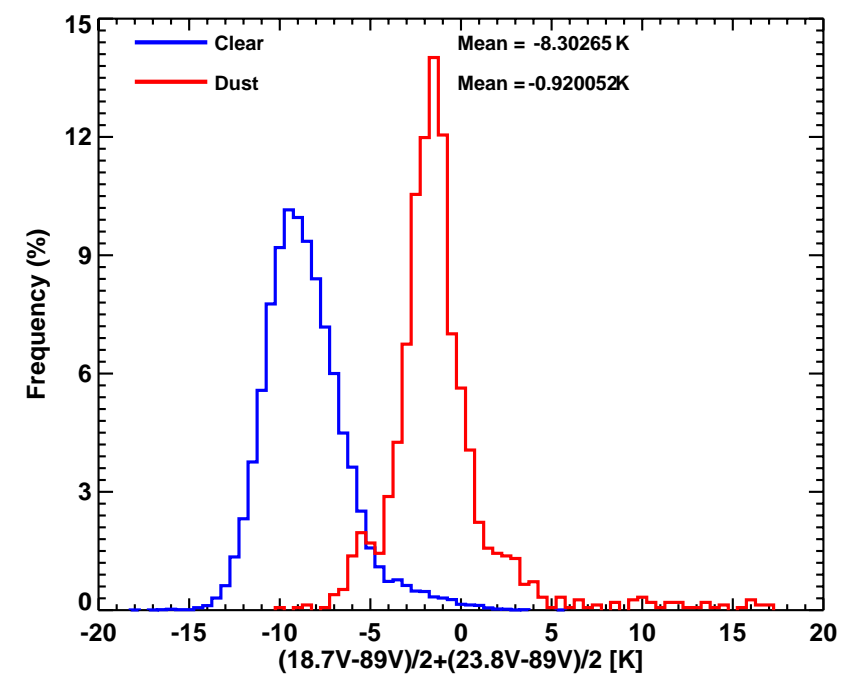

Fig. 3. Comparison of the microwave scattering index i.e. SCAT $=(18.7 \mathrm{~V}-89 \mathrm{~V}) / 2+(23.8 \mathrm{~V}-89 \mathrm{~V}) / 2$ between clear and dusty data. The blue color represents the clear sky. The red color is the dust cases.

Table 2. Surface emissivity of vertical and horizontal channels for six AMSR-E frequencies.

\begin{tabular}{rrr}
\hline \multirow{2}{*}{ Frequency $(\mathrm{GHz})$} & \multicolumn{2}{c}{ Surface Emissivity } \\
\cline { 2 - 3 } & vertical & horizontal \\
\hline 6.9 & 0.882 & 0.749 \\
10.7 & 0.888 & 0.752 \\
18.7 & 0.901 & 0.763 \\
23.8 & 0.900 & 0.772 \\
36.5 & 0.904 & 0.785 \\
89.0 & 0.940 & 0.830 \\
\hline
\end{tabular}

cal polarization (Fig. 1a), the brightness temperature spectra display a distinct feature, especially at high frequency. The difference between the $\mathrm{Tb}$ of vertical polarization for clear and sandy days can reach $10.5 \mathrm{~K}$ at $89 \mathrm{GHz}$. This brightness temperature depression is presumably attributed to the extinction of the upwelling surface microwave radiation by the dust particles. At low frequencies, the attenuation of microwave radiation by dust aerosol is small at the vertical polarization, because the dust particle size parameters are small at these long wavelengths. At the horizontal polarization (Fig. 1b), the brightness temperature for the dust case is initially larger than that of clear sky at lower frequencies and then becomes smaller at $89 \mathrm{GHz}$. We can explain this oscillated feature in terms of relative contributions from surface, and dust emission and scattering. For clear sky conditions, the brightness temperature at $6.9 \mathrm{GHz}$ is lower because of the low surface emissivity and a lack of atmospheric emission. When dust storms occur, the brightness temperature increases as a result of increasing atmospheric emission from

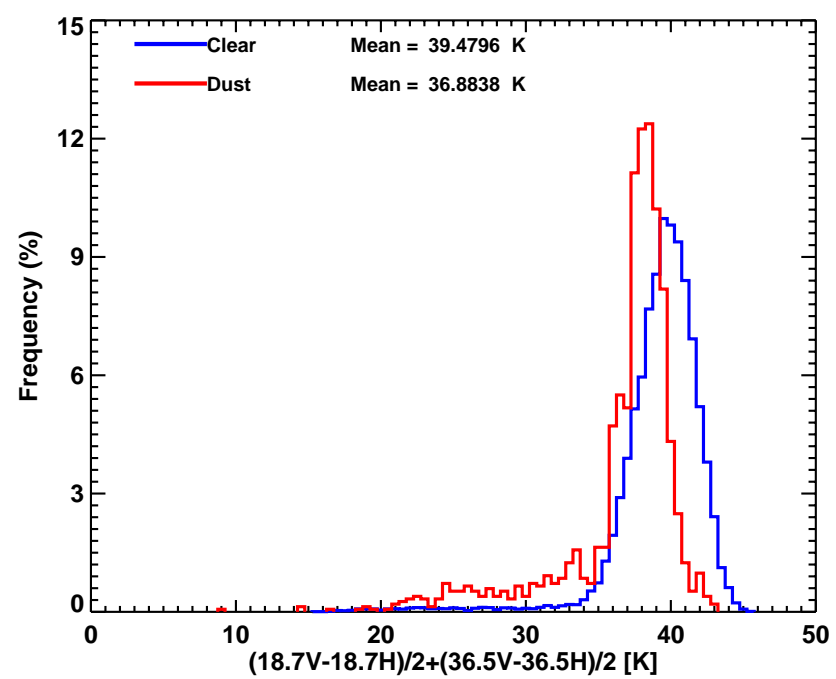

Fig. 4. Comparison of the microwave polarized brightness temperatures difference i.e. $\mathrm{PTD}=(18.7 \mathrm{~V}-89 \mathrm{~V}) / 2+(23.8 \mathrm{~V}-89 \mathrm{~V}) / 2$ between clear and dusty data. The blue color represents the clear sky. The red color is the dust cases.

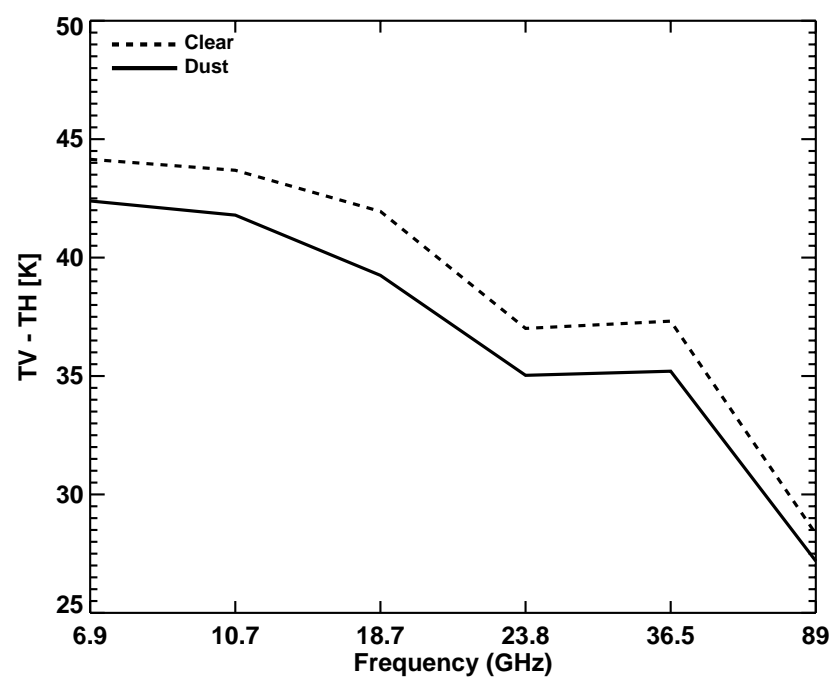

Fig. 5. Comparison of the average polarized brightness temperature difference as a function of frequency.

the dust. At higher frequencies, the surface emissivity is relatively higher at horizontal polarization, where the brightness temperature difference between clear and dust conditions mainly depends on whether there are large particles that produce significant scattering. 

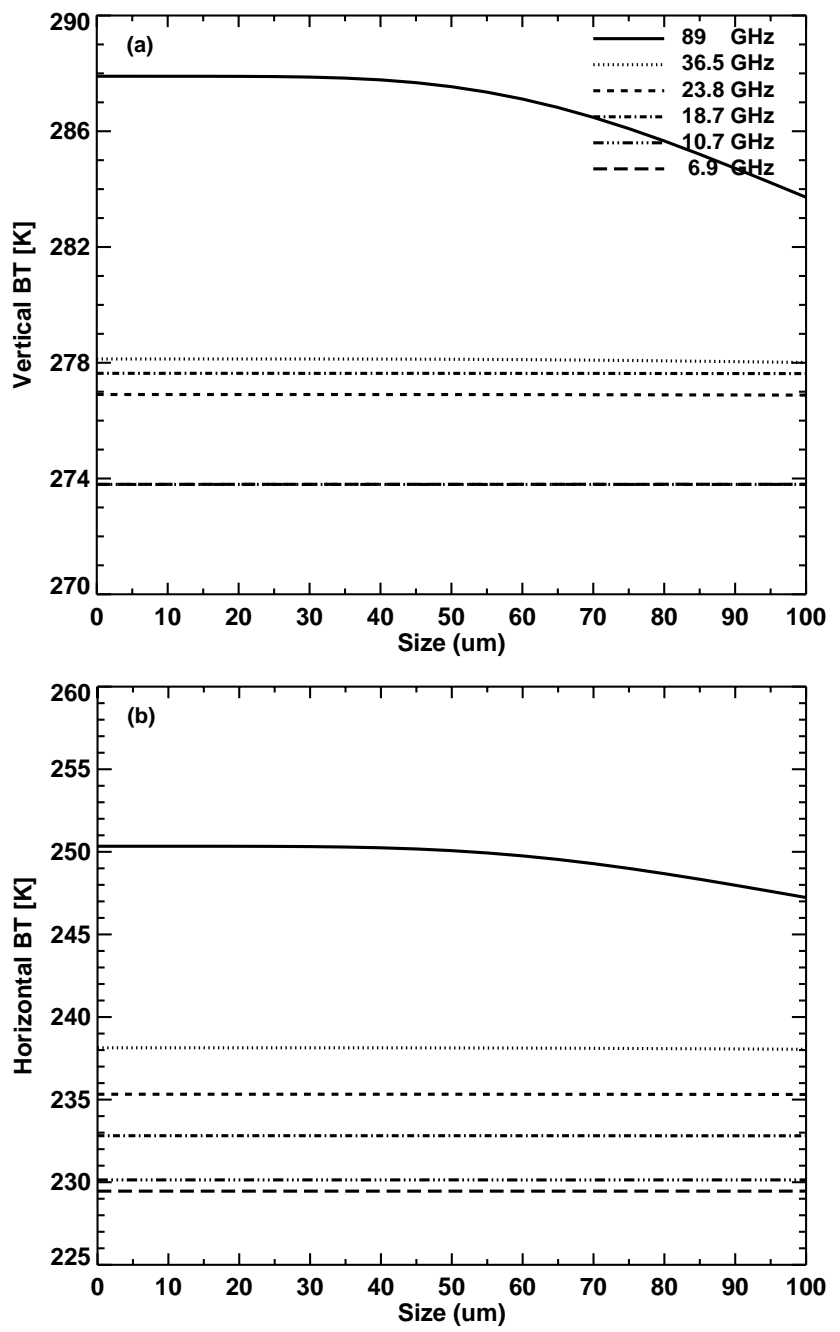

Fig. 6. Sensitivity of brightness temperature variation to dust particle size for six AMSR-E frequencies. The dielectric constant is 5.52-0i.

To quantify the scattering intensity, Basist et al. (1996) defines a scattering index. Here, we revise it by using the brightness temperature difference between 23.8 and $89 \mathrm{GHz}$ to identify the scattering effects of dust aerosols. Figure 2 shows the scatter plot of $\mathrm{T}_{23.8 \mathrm{GHz}(\mathrm{V})}-\mathrm{T}_{89 \mathrm{GHz}(\mathrm{V})}$ against $\mathrm{T}_{23.8 \mathrm{GHz}(\mathrm{H})}-\mathrm{T}_{89 \mathrm{GHz}(\mathrm{H})}$ for eight cases. The scattering indices using the vertical and horizontally polarized measurements are distinct for dust and clear sky groups. For the clear sky groups represented by blue dots, the values of $\mathrm{T}_{23.8 \mathrm{GHz}}-\mathrm{T}_{89 \mathrm{GHz}}$ are small, where the mean scattering indices are $-8.59 \mathrm{~K}$ and $-17.39 \mathrm{~K}$, for the respective different polarizations. In contrast, the mean values of $\mathrm{T}_{23.8 \mathrm{GHz}}-\mathrm{T}_{89 \mathrm{GHz}}$ are much large for dust groups. At horizontal polarization, the mean scattering index is $6.93 \mathrm{~K}$ warmer than the clear groups. It is about $7.41 \mathrm{~K}$ warmer for vertical polarization. Dust particles have scattering effects at high frequencies for both the vertical and horizontal microwave channels.
In Fig. 2, the mean value of $\mathrm{T}_{23.8 \mathrm{GHz}(\mathrm{H})}-\mathrm{T}_{89 \mathrm{GHz}(\mathrm{H})}$ for dust groups is much larger than that for the clear groups, which also indicates that the decrease of brightness temperature at the high frequency is due to the dust particles in the atmosphere but not the surface phenomena. To use the full spectral information from AMSR-E data, we further introduce an index that is based on the brightness temperatures of three vertical polarization channels at $18.7,23.8$, and $89 \mathrm{GHz}$ so that

$\mathrm{SCAT}=(18.7 \mathrm{~V}-89 \mathrm{~V}) / 2+(23.8 \mathrm{~V}-89 \mathrm{~V}) / 2$

Figure 3 displays the probability density functions (PDF) of the SCAT from all pixel-level data for either clear or dust cases. It appears that the clear and dust pixels can be separated between two PDFs. Smaller values of SCAT occur more frequently for clear desert, compared to these from dusty cases. The mean SCATs are $-8.30 \mathrm{~K}$ and $-0.61 \mathrm{~K}$ for clear and dust cases, respectively. Note that for the dust cases, the SCAT can reach $10 \mathrm{~K}$. These extreme values are typically associated with strong dust storms which can lift up more and larger dust particulates and cause stronger scattering. It should be pointed out that the SCAT over Taklamakan desert is typically negative in our study but positive over Sahara from a study by Neale (1990) who used the Special Sensor Microwave Imager (SSM/I) data. This difference may be due to a significant difference in chemical components of the two deserts and/or the calibration problems associated with SSM/I.

Deserts are normally characterized by a large polarization difference in brightness temperature at all microwave frequencies when atmosphere is clear. When dust storms occur, the polarization difference becomes smaller. Here, we define another index in reflecting the polarization change from the dust storms, viz.,

$\mathrm{PTD}=(18.7 \mathrm{~V}-18.7 \mathrm{H}) / 2+(36.5 \mathrm{~V}-36.5 \mathrm{H}) / 2$.

Figure 4 plots the frequency distribution of the polarization difference for clear and the dusty cases. For clear cases, the mean value of the expression is $39.48 \mathrm{~K}$, which is slightly greater than the mean value of dusty cases of $36.72 \mathrm{~K}$. In a dust storm, the dust particles in the air and near surface can distribute randomly. These randomly distributed particles can emit and scatter microwave radiation to all directions, therefore depolarizing surface radiation as shown in Fig. 5. Note that the presence of dust particles does not significantly depolarize surface radiation at high frequencies, because at high frequencies surface polarization difference is not significant.

To further elucidate the scattering properties of dust particles, simulations were conducted using the radiative transfer model. In the model calculations, the dust particles are assumed to be spheres with a normal size distribution. The aerosol concentration over East Asia is often high ( $\mathrm{Li}$ et al., 2007), the average number concentration of dust particles is 

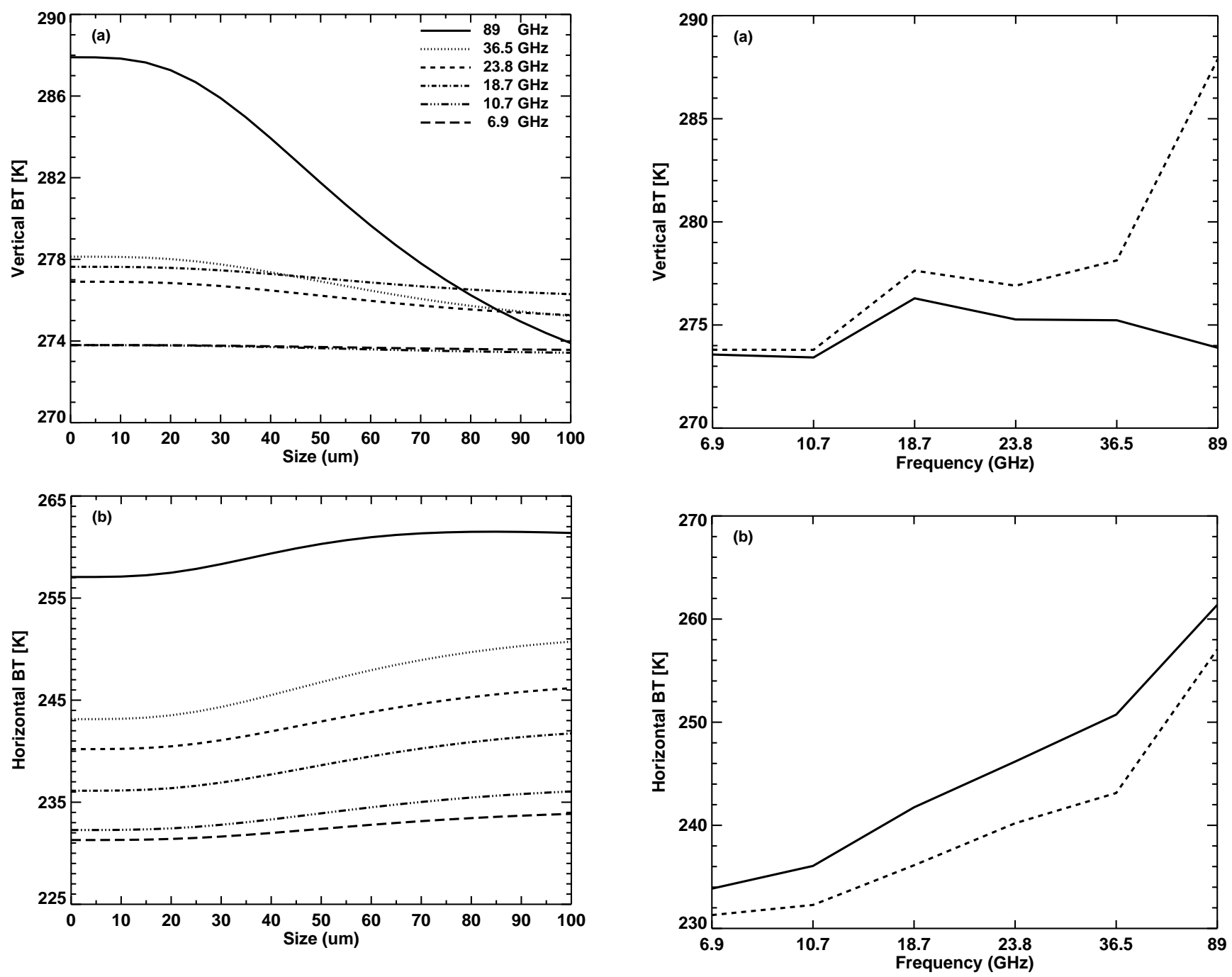

Fig. 7. Sensitivity of brightness temperature variation to dust particle size for six AMSR-E frequencies. The dielectric constant is 5.52-0.024i.

extremely large over desert region and set to be $1700 \mathrm{~cm}^{-3}$ (Cheng et al., 2004). Vertical profiles of temperature, pressure, humidity are from NCEP re-analysis data of 18 March 2005.

Figure 6 shows the model simulation result of the brightness temperature variation as a function of dust particle size without considering dust absorption property. The dielectric constant is $\mathbf{5 . 5 2}$ for dry sand at the six frequencies of AMSRE. It clearly shows that both the vertical- and horizontalpolarization Tbs at the high frequency of $89 \mathrm{GHz}$ are significantly reduced as dust particle size increases. In Fig. 6a, the $\mathrm{Tb}$ is $4.2 \mathrm{~K}$ higher when particle size is $100 \mu \mathrm{m}$ than that in clear sky (i.e. $0 \mu \mathrm{m}$ ) and the difference of Tb between clear and $100 \mu \mathrm{m}$ is $3 \mathrm{~K}$. For the other frequencies from 36.5 to $6.9 \mathrm{GHz}$, because of the wavelengths are much larger than particle sizes, both the vertical- and horizontal-polarization Tbs are almost invariant. Figure 7 is the same as Fig. 6, but

Fig. 8. Comparison of simulated polarized brightness temperature of the dust case on 18 March 2005 and clear sky values of March 2005 as function of frequency. Upper panel is for vertical Tb, lower is for horizontal.

considering dust absorption, the dielectric constant is 5.520.024i. Both scattering and absorption cause the verticalpolarization $\mathrm{Tb}$ at $89 \mathrm{GHz}$ to be reduced rapidly with the increase of particle size. As shown in Fig. 7a, the difference of $\mathrm{Tb}$ between clear $(0 \mu \mathrm{m})$ and $100 \mu \mathrm{m}$ particle size conditions can reach $14 \mathrm{~K}$ for $89 \mathrm{GHz}$. For $36.5,23.8$ and $18.7 \mathrm{GHz}$, the absorption of dust can also damp the microwave radiance penetrating the dust layer and the difference of $\mathrm{Tb}$ between clear $(0 \mu \mathrm{m})$ and $100 \mu \mathrm{m}$ conditions are $2.9 \mathrm{~K}, 1.8 \mathrm{~K}$ and $1.5 \mathrm{~K}$, respectively. In Fig. $7 \mathrm{~b}$, all of the Tbs at the six frequencies become larger and larger with the increase of particle size. Thermal emission could account for this phenomenon. 
Figure 8 is the model-simulated result of clear condition of March 2005 and the dust case on 18 March 2005. Firstly, we set a clear condition and adjust the surface emissivity of both vertical and horizontal channels for the six AMSR-E frequencies to make the simulation have the same values with satellite observed clear sky result. Table 2 shows the emissivity in the model (Karbou, 2003). Comparing with Fig. 1, we can see that both the dashed lines in Fig. 1 and Fig. 8 which represent the $\mathrm{Tb}$ of clear sky have same values at each channel. Then, we add dust particle into the model and simulate the microwave radiance which passes through the dust layer and is received by satellite sensor. In Fig. 8a, the Tb value of solid line at $89 \mathrm{GHz}$ is $274 \mathrm{~K}$ that is much smaller than that of dashed line because of strong dust extinction effect on vertical polarized channel. The feature is consistent with it in Fig. 1a. For the horizontal channel of $89 \mathrm{GHz}$, there is a difference between observation and simulation. In Fig. 1b, the $\mathrm{Tb}$ value of dust at $89 \mathrm{GHz}$ is pronouncedly smaller than that of clear day. But in Fig. 8b, when dust is present, the $\mathrm{Tb}$ value of $89 \mathrm{GHz}$ is $1.3 \mathrm{~K}$ higher than that under clear condition. The microwave brightness temperatures in the vertical polarization are not sensitive to sand particle habit, but it is sensitive to it in horizontal polarization (Hong et al., 2007). Thus, the lack of accurate particle size distribution, shape and dielectric constant may introduce the difference of observation and simulation. We also calculated the PTD using the simulated $\mathrm{Tb}$ values. For clear day, the value of the expression (2) is $37.8 \mathrm{~K}$ and higher than that of sandy day which is $29.52 \mathrm{~K}$. The model results confirm that dust depolarizes surface radiation.

\section{Conclusions and discussions}

AMSR-E brightness temperatures are analyzed for eight dust-storms over Taklamakan Desert during the period between 2003 and 2006; the impacts of dust on microwave radiation are also investigated by a radiative transfer model. Both the observed and the model-simulated results show that the brightness temperatures at high microwave frequencies are depressed due to dust scattering. The dust particles also have some weak depolarization effects on surface microwave emission from deserts. This finding is significant when microwave measurements from space are combined with infrared sensor data. In an infrared algorithm, the brightness temperature differences between 8 and $11 \mu \mathrm{m}$ vs. those between 11 and $12 \mu \mathrm{m}$ can discriminate the dust from clear sky (Ackerman, 1997). However, the most common dust storms in East Asia are those caused by strong winds behind a cold front and generally coexist with cirrus. Because the visibleinfrared radiance is primarily sensitive to the upper cirrus cloud layer, especially when the upper-layer cirrus clouds are thick, the BTD approach can hardly detect dust underneath the cirrus clouds. Since the microwave radiation is not affected by ice clouds, the change in microwave brightness temperature spectrum can be solely associated with dust particle effect when cirrus clouds and dust coexists in the atmosphere. A multi-sensor algorithm has been recently developed to detect all dust storms using VIS-IR (visible-infrared) and microwave measurements (Huang et al., 2007). It is shown that the algorithm can detect cloud-over-dust system while infrared measurements are only for the cloud-free-dust system.

Further investigation of dust effects on microwave still need to be done for us. Some measurements and research works show that dust particles in dust storms can carry charges (KAMRA, 1972), particle shape is non-sphere (Dubovik et al., 2002, 2006; Yang et al., 2007) and particle size distributions are uncertain. All of these should be considered in future work in order to give a perfect theoretical explanation.

Acknowledgement. This research is supported by National Science Foundation of China under grant (40725015 and 40633017) The MODIS and AMSR-E microwave data were obtained from the NASA Earth Observing System Data and Information System, Distributed Active Archive Center (DAAC) at the GSFC.

Edited by: Q. Fu

\section{References}

Ackerman, S. A.: Remote sensing aerosols using satellite infrared observations, J. Geophy. Res., 102(D14), 17 069-17 080, 1997.

Albrecht, B. A.: Aerosols, cloud microphysics and fractional cloudiness, Science, 245, 1227-1230, 1989.

Basist, A., Garrett, D., Ferraro, R., Grody, N. C., and Forsyth, D.: A comparison between snow cover products derived from visible and microwave satellite observations, J. Appl. Mereor., 35, 163177, 1996.

Bréon, F.-M., Tanré, D., and Generoso, S.: Aerosol effect on cloud droplet size monitored from satellite, Science, 295, 834-838, 2002.

Cheng, T., Lu, D., Chen, H., et al.: Physical characteristics of dust aerosol over Hunshan Dake sandland in Northern China, Atmos. Environ., 39, 1237-1243, 2004.

Christopher, M. U. Neale, Mcfraland, M. J., and Chang, K.: LandSurface-Type classification using microwave brightness temperatures from the special sensor microwave/imager, IEEE T. Geosci. Remote Sens., 28(5), 829-838, September 1990.

Delene, D., Rose, W., and Grody, N.: Remote sensing of volcanic ash clouds using the special sensor microwave imager data, J. Geophys. Res., 101, 11 579-11 588, 1996.

DeMott, P. J., Sassen, K., Poellot, M., Baumgardner, D., Rogers, D. C., Brooks, S., Prenni, A. J., and Kreidenweis, S. M.: African dust aerosols as atmospheric ice nuclei, Geophys. Res. Lett., 30, 14, 1732, doi:10.1029/2003GL017410, 2003.

Dubovik, O., Holben, B. N., Lapyonok, T., Sinyuk, A., Mishchenko, M. I., Yang, P., et al.: Non-spherical aerosol retrieval method employing light scattering by spheroids, Geophys. Res. Lett., 29, 10, 1415, 2002. 
Dubovik, O., Alexander, S., Tatyana, L., et al.: The application of spheroid models to account for aerosol particle nonsphericity in remote sensing of desert dust, J. Geophys. Res.,111, D11208, doi:10.1029/2005JD006619, 2006.

El-Askary, H., Sarkar, S., Kafatos, M., and El-Ghazawi, T. A.: Multisensor approach to dust storm monitoring over the nile delta, IEEE T. Geosci. Remote Sens., 41, 2386-2391, 2003.

El-Askary, H., Gautam, R., Singh, R. P., and Kafatos, M.: Dust storms detection over the Indo-Gangetic basin using multi sensor data, Adv. Space Res., 37, 728-733, 2006.

Ferraro, R. R. and Grody, N. C.: Effects of surface conditions on rain identification using the DMSP-SSM/I, Remote Sens. Rev., 11, 195-209, 1994.

Huang, J., Ge, J., and Weng, F.: Detection of Asia dust storm using satellite microwave, visible and infrared measurements, Remote Sens. Environ., 110, 186-191, 2007.

Huang, J., Lin, B., Minnis, P., Wang, T., Wang, X., Hu, Y., Yi, Y., and Ayers, K.: Satellite-based assessment of possible dust aerosols semi-direct effect on cloud water path over East Asia, Geophys. Res. Lett., 33, L19802, doi:2006GL026561, 2006.

Huang, J., Minnis, P., Lin, B., Wang, T., Yi, Y., Hu, Y., SunMack, S., and Ayers, K.: Possible influences of Asian dust aerosols on cloud properties and radiative forcing observed from MODIS and CERES, Geophys. Res. Lett., 33, L06824, doi:10.1029/2005GL024724, 2006.

Huang, J., Minnis, P., Yi, Y., et al.: Summer dust aerosols detected from CALIPSO over the Tibetan Plateau, Geophys. Res. Lett., 34, L18805, doi:10.1029/2007GL029938, 2007.

Hong, G., Yang, P., Weng, F., and Liu, Q.: Microwave scattering properties of sand particles: Application to the simulation of microwave radiances over sandstorms, J. Quant. Spectrosc. Ra., 109, 684-702, doi:10.1016/j.jqsrt.2007.08.018, 2007.

KAMRA, A. K.: Measurements of the electrical properties of dust storms, JGR, 77, 5856-5869, 1972.

Karbou, F., Eymard, L., Prigent, C., and Pardo, J. R.: Microwave land surface emissivity assessment using AMSU-B and AMSUA measurements, IEEE, 4, 2302-2304, 2003

Lau, K.-M., Kim, K.-M.: Observational relationships between aerosol and Asian monsoon rainfall and circulation, Geophys. Res. Lett., 33, L21810, doi:10.1029/2006GL027546, 2006.
Legrand, M., Plana-Fattori, A., and N'Doume, C.: Satellite detection of dust using the IR imagery of Meteosat, 1, Infrared difference dust index, J. Geophys. Res., 106, 18 251-18 274, 2001.

Li, Z., Chen, H., and Cribb, M.: Preface to special section on East Asian Studies of Tropospheric Aerosols: An International Regional Experiment (EAST-AIRE), Geophys. Res. Lett., 112, D22S00, doi:10.1029/2007JD008853, 2007.

Prata, A. J.: Observations of volcanic ash clouds in the 10-12 micrometer window using AVHRR/2 data, Int. J. Remote Sens., 10, 751-761, 1989.

Prata, A. J. and Grant, I. F.: Retrieval of microphysical and morphological properties of volcanic ash plumes from satellite data: Application to Mt. Ruapehu, New Zealand, Q. J. Roy. Meteor. Soc., 127, 2153-2179, 2001.

Rosenfeld, D., Rudich, Y., and Lahav, R.: Desert dust suppressing precipitation: a possible desertification feedback loop, P. Natl. A. Sci., 98(11), 5975-5980, 2001.

Slingo, A., Ackerman, T. P., Allan, R. P., et al.: Observations of the impact of a major Saharan dust storm on the atmospheric radiation balance, Geophys. Res. Lett., 33, L24817, doi:10.1029/2006GL027869, 2006.

Twomey, S., Piepgrass, M., and Wolfe, T. L.: An assessment of the impact of pollution on global cloud albedo, Tellus, 36B, 356366, 1984.

Wentz, F. J.: Algorithm theoretical basis document: AMSR ocean algorithm, Remote Sens. Sys., Tech. Rep., 28, 110398, Tech. Report no. 110398, 28pp., Santa Rosa, CA, USA, 1998.

Yang, P., Feng, Q., Hong, G., Kattawar, G. W., Wiscombe, W. J., Mishchenko, M. I., et al.: Modeling of the scattering and radiative properties of nonspherical dust particles, J. Aerosol. Sci., 38, 995-1014, 2007.

Yang, D., Shang, K., and Wang, S.: Dust Storm (in Chinese), Meteorology Press, Beijing, China, 2003.

Weng, F.: A multi-layer discrete-ordinate method for vector radiative transfer in a vertically-inhomogeneous, emitting and scattering atmosphere-I. Theory, J. Quant. Spectrosc. Radiat. Transfer, 47, 19-33, 1992.

Weng, F.: A multi-layer discrete-ordinate method for vector radiative transfer in a vertically-inhomogeneous, emitting and scattering atmosphere-II, Appl. J. Quant. Spectrosc. Radiat. Transfer, 47, 35-42, 1992. 